\title{
Ontogenetic differences in expressed fear of context following aversive conditioning
}

\author{
PHILIPP J. KRAEMER, CHRISTOPHER K. RANDALL, and TIMOTHY J. CARBARY \\ University of Kentucky, Lexington, Kentucky
}

A conditioned-emotional-response procedure was used to compare acquired fear of a light conditioned stimulus and the conditioning context in 17-, 21-, and 60-day-old rats. Separate groups at each age received either light and shock paired, light and shock unpaired, shock alone, or neither light nor shock before testing $24 \mathrm{~h}$ later. Differences in learned context fear, measured on the basis of group differences in baseline activity prior to presentation of the light, appeared in 17 and 21-day-old rats but not in adult rats. Activity also declined significantly over the baseline intervals at the two younger ages among all groups that received shock; activity levels in adults did not change over the baseline intervals. Although all three ages expressed conditioned fear of the light, indexed as a decrement in activity during the light relative to the no-light baseline period, adults also exhibited pseudoconditioning and sensitization. These results are discussed in terms of possible ontogenetic differences in context learning.

The purpose of this study was to examine conditioning of context fear in preweanling (17-day-old), weanling (21day-old), and adult (60- to 90 -day-old) rats given different types of experience with a light conditioned stimulus (CS) and a footshock unconditioned stimulus (US). Different groups at each age received light and shock paired (Group L+S), light and shock unpaired (Group L/S), shock alone (Group S), or neither light nor shock (Group N) before testing. A 3-min test period was divided into three 1-min intervals, with activity recorded separately during each interval by an ultrasonic motion detector. The light appeared throughout Interval 3, and no programmed stimuli were presented during the first two intervals.

Behavior during Intervals 1 and 2 provides an index of baseline activity, which should differ across groups in accord with the degree of context fear induced by the various light-shock arrangements (Baker \& Mercier, 1982). Some recent pilot data suggested that important changes in activity may also occur over the first two baseline intervals and that these changes are perhaps influenced by age and training experience.

\section{METHOD}

\section{Subjects}

Subjects were Sprague-Dawley-derived rats purchased from a local distributor. There were 56 preweanlings ( 17 days old) taken from five different litters, 56 weanlings ( 21 days old) taken from six different litters, and 48 adults (60-90 days old). The subjects were housed either individually in stainless steel hanging cages (adults) or in opaque plastic maternity cages with both parents present (preweanlings and weanlings). The animals were located in the same climate-controlled vivar-

This research was supported by a grant from the University of Kentucky Research Foundation to P.J.K. The authors wish to thank William Crouch for his assistance in completing this project. Correspondence should be addressed to P. J. Kraemer, Department of Psychology, University of Kentucky, Lexington, KY 40506-0044. ium, which operated on a 16:8-h light:dark cycle. Conditioning and testing occurred during the light phase of the cycle. Each subject had free access to food and water throughout the experiment.

\section{Apparatus}

The test box was housed in an animal isolation chamber equipped with a ceiling-mounted 7.5-W lamp, which served as the CS. An ultrasonic motion detector (see Moye \& Rudy, 1985) was mounted on the front wall of the isolation chamber, opposite to the wall containing a ventilation fan. The motion detector consisted of a circular transmitter and receiver, each $2.4 \mathrm{~cm}$ in diameter, which were mounted $10 \mathrm{~cm}$ above the chamber floor and spaced $5 \mathrm{~cm}$ apart. Motion-induced air-current disturbances were detected as frequency discrepancies by the receiver and initiated closure of an electromechanical relay. Each relay closure defined one activity count.

The chamber floor was a $36-\mathrm{cm}$ Plexiglas frame that contained stainless steel rods $.6 \mathrm{~cm}$ in diameter and spaced $1 \mathrm{~cm}$ apart for the adults or $.3 \mathrm{~cm}$ in diameter and spaced $.5 \mathrm{~cm}$ apart for the two younger ages. The grid floor was placed on the floor of the isolation chamber, centered under the ceiling light. The grids were attached to a Lafayette Instruments scrambled shock generator (Model 82404-SS). Fresh pine shavings were placed underneath the grids.

A floorless Plexiglas box, painted flat gray, was placed directly on the grids. It measured $36 \mathrm{~cm}$ (length) $\times 25 \mathrm{~cm}$ (width) $\times 25 \mathrm{~cm}$ (height) and was equipped with two holes in the front wall that allowed the transmitter and receiver of the activity monitor to extend slightly inside the box. The box was covered by a transparent Plexiglas lid. A three-chamber gray Plexiglas partition was placed inside the box during the conditioning phase of the experiment. This unit divided the test box into three equal-size chambers, each measuring $24 \mathrm{~cm}$ (length) $\times 11 \mathrm{~cm}$ (width) $\times$ $25 \mathrm{~cm}$ (height). All stimulus events and response recording were controlled by a Commodore 64 computer and a Lafayette Instruments interface (Model 1195-02).

\section{Procedure}

The subjects at each age were randomly assigned to four groups $(n=$ 14 for preweanlings and weanlings, $n=12$ for adults). For Groups $\mathrm{L}+\mathrm{S}$ and $\mathrm{L} / \mathrm{S}$, the $\mathrm{CS}$ was a 15 -sec presentation of the ceiling light. For Groups $\mathrm{L}+\mathrm{S}, \mathrm{L} / \mathrm{S}$, and $\mathrm{S}$, the US was a $0.75-\mathrm{sec}, 1-\mathrm{mA}$ scrambled footshock. The subjects were conditioned in groups of 3 but tested individually. Conditioning involved 12 presentations of the US, separated by a variable-time (VT) 120 -sec intertrial interval. For Group L+S, each US presentation was immediately preceded by the light CS. For Group L/S, CSs and USs were explicitly unpaired. No CSs were pre- 
sented to Group $\mathrm{S}$. The subjects in Group $\mathrm{N}$ remained in the home cage and were not handled prior to testing.

Testing occurred approximately $24 \mathrm{~h}$ after conditioning. Each subject received a 3-min test session, divided into three 1-min intervals. The light was presented throughout Interval 3, and no programmed stimuli appeared during Intervals 1 and 2 .

\section{RESULTS}

\section{Baseline Performance}

Mean activity counts for each group at each age during Interval 1 appear in Table 1 . All statistical tests were evaluated at a .05 level of significance. Group differences appeared among preweanlings $[F(3,52)=2.82]$ and weanlings $[F(3,52)=3.63, p<.01]$ but not among adults $[F(3,44)=.89]$. Individual group comparisons (NewmanKeuls test, Keppel, 1991) revealed that preweanlings in Group S displayed significantly fewer activity counts than did those in Group N, but none of the remaining group differences at this age reached significance. Among the weanlings, activity counts of Group $\mathrm{L}+\mathrm{S}$ were significantly higher than were those of Groups $\mathrm{L} / \mathrm{S}$ and $\mathrm{S}$; none of the remaining differences in activity counts reached significance.

\section{Test Performance}

To make functional comparisons across the three ages, we analyzed mean activity counts for each of the three test intervals. Separate analyses were performed for each group at each age. Mean activity counts for all groups at each of the three ages appear in Figure 1. It can be seen that for the subjects in Group L+S, significant changes in activity appeared across the three test intervals in preweanlings $[F(2,26)=14.1]$, weanlings $[F(2,26)=53.4]$, and adults $[F(2,22)=18.6]$. Individual group comparisons further indicated that preweanlings and weanlings both showed the same continuous decline in activity over the test session; mean activity counts differed significantly between Intervals 1 and 2, Intervals 2 and 3, and Intervals 1 and 3 . In contrast, activity counts in adults differed significantly only between Intervals 2 and 3 .

Activity changed significantly over the test session for Group L/S among preweanlings $[F(2,26)=10.7]$, weanlings $[F(2,26)=27.4]$, and adults $[F(2,22)=22.3]$. The preweanlings and weanlings again displayed the same pattern: a significant drop in activity counts between Intervals 1 and 2 and between Intervals 1 and 3 but not between Intervals 2 and 3. The Group L/S adults behaved much like Group $\mathrm{L}+\mathrm{S}$ adults: they showed a significant decrement in activity between Intervals 2 and 3 but not between Intervals 1 and 2 .

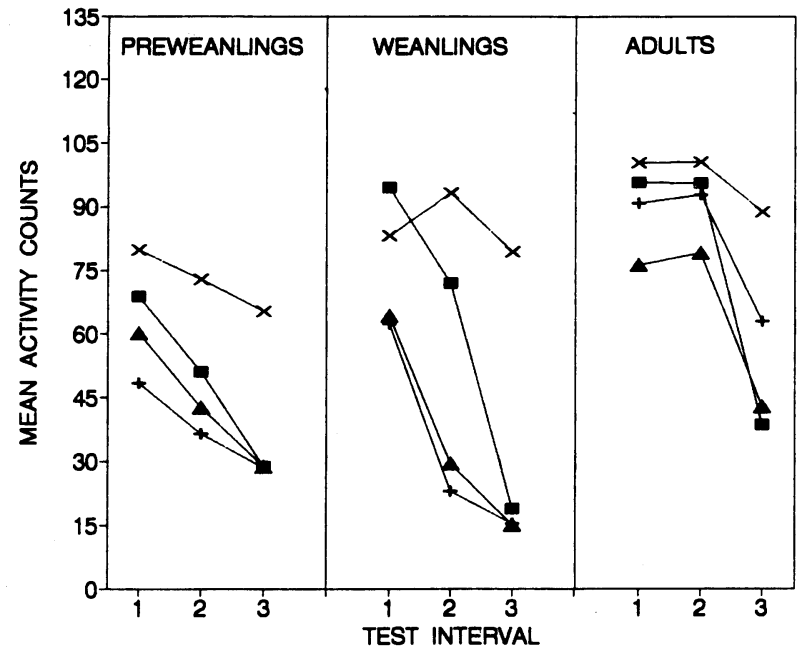

Figure 1. Mean activity counts for preweanlings, weanlings, and adults in Group L+S (square), Group L/S (triangle), Group S (+), and Group $\mathbf{N}(X)$. A light conditioned stimulus appeared throughout Interval 3 but not during Intervals 1 or 2 .

Activity counts for Group $\mathrm{S}$ also declined significantly across the test session in preweanlings $[F(2,26)=5.6]$, weanlings $[F(2,26)=43.2]$, and adults $[F(2,22)=5.7]$. Preweanlings showed a significant decrement in activity counts only between Intervals 1 and 3, whereas weanlings showed a significant decrement in activity counts between Intervals 1 and 2 and between Intervals 1 and 3 but not between Intervals 2 and 3 . In contrast, the adults showed no significant change in activity counts between Intervals 1 and 2 but did show a significant change between Intervals 2 and 3.

For Group N, weanlings were the only age group that showed a significant difference in activity counts across the test session $[F(2,26)=3.74]$. This difference resulted from a significant difference in activity counts between Intervals 1 and 3.

\section{DISCUSSION}

Baker and Mercier (1982) have shown that baseline performance following a conditioned-emotional-response (CER) procedure can provide a valuable index of context learning in adults. They reported that context-shock associations can be detected as between-group differences in baseline behavior. The current results show that the same measure can be used with younger rats and that context fear produced by an aversive CER procedure may be even more robust in 17- and 21-day-old rats than in adults.

Ontogenetic differences in acquired context fear can be inferred from two aspects of the present findings. First, activity counts during Inter-

Table 1

Mean Activity Counts During Interval 1 for Preweanlings, Weanlings, and Adults in Experiment 1

\begin{tabular}{|c|c|c|c|c|c|c|c|c|}
\hline \multirow[b]{2}{*}{ Age } & \multicolumn{2}{|c|}{ Group L+S } & \multicolumn{2}{|c|}{ Group L/S } & \multicolumn{2}{|c|}{ Group S } & \multicolumn{2}{|c|}{ Group N } \\
\hline & $M$ & $S E$ & $M$ & $S E$ & $M$ & $S E$ & $M$ & $S E$ \\
\hline Preweanling & 68.8 & 8.6 & 60.1 & 6.0 & 46.4 & 7.2 & 79.9 & 9.5 \\
\hline Weanling & 94.4 & 9.1 & 64.3 & 9.0 & 62.4 & 7.7 & 100.2 & 6.3 \\
\hline Adult & 95.8 & 9.5 & 76.2 & 11.0 & 90.8 & 14.2 & 88.4 & 9.2 \\
\hline
\end{tabular}


val 1 were found to differ across training conditions in preweanlings and weanlings but not in adults. Group $S$ preweanlings displayed significantly less activity during Interval 1 than did Group $\mathbf{N}$ preweanlings, a finding consistent with the expectation that shock alone produces the strongest context fear; in the shock-alone condition, there is no other stimulus to compete with the context for associative strength.

The same conclusion, however, does not fit the performance of the weanlings; at this age, the activity counts of the Group $S$ weanlings were not significantly different from those of the Group $\mathrm{N}$ weanlings. There was, however, an indication that whatever the degree of context fear acquired by the weanlings, that degree was substantially reduced when shocks were signaled; activity counts during Interval 1 were significantly greater in Group L+S weanlings than in either Group $S$ or Group L/S weanlings. Perhaps in Group $\mathrm{L}+\mathrm{S}$, the light served as a reliable signal for shock, which consequently reduced the degree of fear that would otherwise have accrued to the context.

A second indication of an ontogenetic difference in learned context fear is found in the nature of the changes in activity that occurred between the two baseline intervals (Intervals 1 and 2). None of the adult groups changed activity significantly across Intervals 1 and 2 , but weanlings that were shocked (Groups $L+S, L / S$, and S) displayed a significant decrement in activity from Interval 1 to 2 , and preweanlings in Groups $\mathrm{L}+\mathrm{S}$ and $\mathrm{L} / \mathrm{S}$ showed the same effect. This developmental trend can again be explained in terms of ontogenetic differences in context learning. The younger rats may have formed stronger associations between the test context and shock than did the adults, and this learning may have been gradually expressed as the test session continued.

The absence of between-group differences during Interval 1 and the absence of a change in activity between Intervals 1 and 2 among adults contrasts with the data from the two younger ages. One interpretation of these differences is that the adults did not acquire as strong a fear of context as did the weanlings and preweanlings. This conclusion is compatible with evidence that younger rats may be more inclined than adults to process contextual information (Lariviere, Chen, \& Spear, 1990 Solheim, Hensler, \& Spear, 1980). We do not suggest, however, that context fear would not develop in adults under different parameters. We also cannot exclude the possibility that adults acquired context-fear associations but failed to express that learning. Thus, our conclusion is that with the current procedure and parameters, we obtained evidence of learned context fear in preweanlings and weanlings but not in adults.

The final aspect of these results that needs to be discussed concerns the degree of nonassociative fear expressed by adults. Although the performance of Group $\mathrm{L}+\mathrm{S}$ is consistent with an associative account of acquired fear, the performance of adults in Groups L/S and $S$ is not. The latter two groups were never exposed to contiguous pairings of light and shock. Consequently, the traditional interpretation of these effects would be that Group L/S displayed pseudoconditioning and Group S displayed sensitization. Pseudoconditioning and sensitization have typically been regarded as nonassociative learning phenomena and are often the basis for rejecting cases of putative learned fear (LoLordo, 1979). Conditioned excitation in adults has sometimes appeared, however, with randomized presentations of CSs and USs (Ayres, Benedict, \& Witcher, 1975; Benedict \& Ayres, 1972; Kremer, 1971, 1974). More recently, Papini and Bitterman (1990) strongly criticized the contingency assumption, and they argued that there is no convincing evidence that a correlation between a CS and a US is either necessary or sufficient to produce conditioned excitation.

The conditioning parameters used in Experiment 1 may be especially likely to induce conditioned excitation in the absence of a CS-US correlation. There were few trials, the interstimulus interval was relatively short, and the duration of the training session was brief. These conditions may make it particularly difficult for the subject to detect the sig- naling properties of the light. What the subject may learn, instead, is that particular events that occur within the same temporal band are related. In Experiment 1, light and shock occurred within the same time span, as defined by session length, which may have induced adults in Group L/S to identify the light as an fear-evoking stimulus.

The sensitization effect shown by adults, however, indicates that the mere occurrence of shock was sufficient to evoke substantial fear of a novel light. Although sensitization could be dismissed as an unfortunate experimental artifact, we prefer to consider the possibility that it may provide important insights into the learning process, especially with respect to ontogeny. For example, only adults showed a significant sensitization effect, as indicated by the significant decline in activity counts shown by Group $S$ between Intervals 2 and 3. Although this response tendency may reflect genuine fear of the light itself, it is also possible that the light had some indirect effect on adult behavior. The light was not only a punctate stimulus, but it also provided more intense illumination of the test context. Perhaps weak context-shock associations that were established in adults were more effectively activated by the improved illumination provided by the test light. Thus, the reduction in activity expressed by adults in Group $S$ might actually reflect heightened fear of a more salient context.

\section{REFERENCES}

Ayres, J. J. B., Benedict, J. O., \& Witcher, E. S. (1975). Systematic manipulation of individual events in a truly random control in rats. Journal of Experimental Psychology: Animal Behavior Processes, 88, 97-103.

Baker, A. G., \&ercier, P. (1982). Prior experience with the conditioning events: Evidence for a rich cognitive representation. In $\mathbf{M}$. L. Commons, R. J. Hernstein, \& A. R. Wagner (Eds.), Quantitative analysis of behavior (Vol. 3, pp. 117-143). Cambridge, MA: Ballinger.

Benedict, J. O., \& Ayres, J. J. B. (1972). Factors affecting conditioning in a truly random control procedure in the rat. Journal of Comparative \& Physiological Psychology, 78, 323-330.

KePPEL, G. (1991). Design and analysis. Englewood Cliffs, NJ: Prentice-Hall.

KREMER, E. F. (1971). Truly random and traditional control procedures in CER conditioning in the rat. Journal of Comparative \& Physiological Psychology, 76, 441-448.

KREMER, E. F. (1974). The truly random control procedure: Associative or non-associative effects in the rat. Journal of Comparative \& Physiological Psychology, 74, 203-210.

Lariviere, N. A., Chen, W., \& Spar, N. E. (1990). The influence of olfactory context on Pavlovian conditioning and its expression in preweanling (16-day-old) and adult rats. Animal Learning \& Behavior, 18, $179-190$.

LoLoRdo, V. M. (1979). Classical conditioning: The Pavlovian perspective. In M. E. Bitterman, V. M. LoLordo, J. B. Overmier, \& M. E. Rashotte (Eds.), Animal learning (pp. 25-126). New York: Plenum.

MOYE, T. B., \& RUDY, J. W. (1985). Ontogenesis of learning: VI. Learned and unlearned responses to visual stimulation in the infant hooded rat. Developmental Psychobiology, 18, 395-409.

Papini, M. R., \& Bitterman, M. E. (1990). The role of contingency in classical conditioning. Psychological Review, 97, 396-403.

Solheim, G. S., Hensler, J. G., \& SPEAR, N. E. (1980). Age-dependent contextual effects on short term active avoidance retention in rats. Behavioral \& Neural Biology, 30, 250-259.

(Manuscript received December 16, 1991.) 